\title{
A measure of marketing price transmission in the Red Onion Market of Sri Lanka
}

\author{
Mr.K.Mathusuthan ${ }^{1}$, Dr.K.Sooriyakumar ${ }^{2}$ \\ Department of Agricultural Economics, Faculty of Agriculture, University of Jaffna, Sri Lanka
}

\begin{abstract}
In the past there were several protectionist trade policies to safeguard the local onion production. This study examines their impact by means of nominal and effective protection rates and competiveness in resource utilization by competitiveness coefficient. There is a long-run co-integration relationship between the farm and the retail prices marketing margin resulting from this long-run relationship cause asymmetric short-run dynamic adjustments between the farm and the retail prices Welfare distribution among stakeholders is measured by classical welfare analysis. The analysis indicates that both big and red onion producers are noticeably protected by the trade policies and receive returns greater than they would get under a free market condition. Trade policies benefit consumers over producers. Gains to the nation are substantial.
\end{abstract}

Keywords — Sri Lanka, Red Onion market, Transmission rate, onion production, farm.

\section{INTRODUCTION}

Sri Lanka imports annually about 34,000 metric tons (mt) (DCS, 2009) of large onion valued at approximately Rs.300 million. If the country is to be self sufficient in onions, local production must be increased by about 400 percent. Cultivation of the crop, which has specific environmental requirements, is presently restricted to a few agro-ecological regions of the dry zone. It should be possible, however to cultivate adapted varieties, fertilizer and water management.

Onion is a vital spice crop in Sri Lankan economy. Two types of onion are grown and consumed in Sri Lanka: the big onion (Allium cepa L.) and shallot called red onion (A. cepa var. ascalonium), which are close substitutes in local cuisine. Sri Lanka is near self-sufficient in red onion, importing only $10 \%$ of the requirement. However, about $70 \%$ of big onion requirement in imported at a cost of around Rs. 6 billion. Government, is therefore striving to achieve self-sufficiency in big onion by year 2015. Thus, onion production is under continuous surveillance and, protectionist trade policies are continuously modified and implemented to promote and safeguard the local cultivation. Sri Lanka grows big onions only seasonally and harvests $90 \%$ of its local production in the months August to October, before the October rains. Therefore, in order to help the local onion producer, the government slaps an import levy in usual practice to avoid oversupply.

Big onion is an important cash crop cultivated in Sri Lanka. Local production of big onion, which is approximately 81,707 MT per year, is not sufficient to meet the annual demand of big onion approximately 203,993 MT per year (DCS, 2009). Unavailability of good quality seeds of recommended varieties in adequate quantities is considered as the main constraint for increasing production of big onion in Sri Lanka (Mettananda, 2006). Furthermore, the quality of the imported big onion true seeds is not up to standard as they reach the country through illegal routes due to export restrictions in India (Edirimanna, 2003). Poor germination and blubbing, high thick neck percentage and low yield are characteristic to such seeds (Edirimanna and Rajapakshe, 2003)

\section{MODEL AND METHODS}

A TVECM is a Vector Auto Regression (VAR) model with a well-specified long run relationship and in which regime changes introduce non-linearities. In the linear VECMs even the smallest deviation from the long run already leads to an adjustment toward the long run relationship, whereas in the TVECMs the adjustment is assumed to be costly. The adjustment takes place only if the benefits of changing the price exceed the costs or the marketing margin.

In the literature above it is noted that changes in the marketing margin may cause an asymmetric price transmission. In this case, the use of the VAR models or the vector error correction linear models (VECM) would be inappropriate. This paper therefore applies a two-regime TVECM (nonlinear model) based on Von Carmon Taubadel (1998) and Meyer (2004). The error correction term serves as the threshold variable, separating the transaction cost variation into two regimes to create a nonlinear threshold model. In the following, we first briefly introduce the threshold model and then discuss our empirical model. 


\section{RESEARCH METHODOLOGY}

The threshold autoregressive model developed by Tong (1978) and Tong and Lim (1980) uses an optimal threshold value to divide the short-run dynamic status of one economic indicator into two regimes. When there are multiple (two) regimes, the threshold model could be transformed as:

$$
\begin{gathered}
Z_{t}=\left(A_{1}+\phi_{1} z_{t-i}\right) I\left(q_{t-d}>\gamma\right)+\left(A_{2}+\phi_{2, i} Z_{t-i}\right)\left(1-I\left(q_{t-d}>\gamma\right)\right)+\varepsilon \\
Z_{t}=\left[\begin{array}{l}
g_{t} \\
i_{t}
\end{array}\right]_{2 \times 1}, A_{1}=\left[\begin{array}{c}
\alpha_{10} \\
\beta_{10}
\end{array}\right]_{2 \times 1}, A_{2}=\left[\begin{array}{c}
\alpha_{20} \\
\beta_{20}
\end{array}\right]_{2 \times 1} \\
\phi_{1}=\left[\begin{array}{c}
\alpha_{1,11 \ldots} \\
\alpha_{1,1 p}, \alpha_{1,21 \ldots} \alpha_{1,2 p} \\
\beta_{1,11 \ldots} \beta_{1,1 p}, \beta_{1,21 \ldots} \beta_{1,2 p}
\end{array}\right]_{2 \times 2 p} \quad \phi_{1}=\left[\begin{array}{c}
\alpha_{2,11 \ldots} \ldots \\
\alpha_{2,1 p}, \alpha_{2,21 \ldots} \alpha_{2,2 p} \\
\beta_{2,11 \ldots} \beta_{2,1 p}, \beta_{2,21 \ldots} \ldots \beta_{2,2 p}
\end{array}\right]_{2 \times 2 p}
\end{gathered}
$$

where $\mathrm{p}$ is the lag length; $q_{t-d}$ is the threshold variable, and $d$ is the delay parameter; $\gamma$ is the threshold value; and the error term $\varepsilon$ has the properties such that $\varepsilon=\left(\varepsilon_{1} * \varepsilon_{2} *\right) \sim$ iid, $E\left(\varepsilon_{t} \mid \Omega_{t-1}\right)=0$, and $E\left(\varepsilon_{1}^{2} t \mid \Omega_{t-1}\right)=\sigma^{2}$ where $\Omega_{t-1}$ is the information set in period $t-1 ; I(\cdot)$ are the indicator functions of regimes, and it is assumed that $I\left(q_{t-d}>\gamma\right)=1$ if there exist regimes and $I\left(q_{t-d} \leq\right.$ $\gamma)=0$ otherwise.

We must examine the existence of the threshold effect in equation (1) before estimating the threshold model. We follow the approach of Tsay (1998) to test the linearity of the model. The null hypothesis is that the model is a linear model-and the alternative hypothesis is that the model is a nonlinear model. Tsay (1998) employs the recursive least squares method (RLS) to obtain the predictive residual of the arranged auto-regression (ARR) to build the test statistic based on the standardized predictive residual. For detailed discussion of the Tsay linearity test, please refer to Tsay (1998).

If the null hypothesis is rejected, which indicates that the model is nonlinear, then the next step is to find the values of the two parameters, the delay parameter $d$ and the threshold value $\gamma$. Suppose that $p$, $q$, and the regimes are known. The threshold variable $z_{t-d}$ determines the appearance of the model in two regimes.

$$
y_{t}= \begin{cases}X_{t}^{y} \phi_{1}+\sum_{1}^{1 / 2} a_{t} & \text { If } z_{t-d}>\gamma \\ X_{t}^{y} \phi_{2}+\sum_{2}^{1 / 2} a_{t} & \text { If } z_{t-d} \leq \gamma\end{cases}
$$

If $\gamma$ and $\mathrm{d}$ are given, then the above equation can be viewed as having two independent linear regressive models, where $\Phi_{i}$ and $\Sigma$ are obtained as follows:

$$
\phi_{i}(\gamma, d)=\left(\sum_{t}^{(i)} X_{t} X_{t}^{F}\right)^{-1}\left(\sum_{t}^{(i)} X_{t} y_{t}^{F}\right), \hat{\Sigma}_{\mathrm{i}}(\gamma, \mathrm{d})=\sum_{\mathrm{t}}^{(\mathrm{i})}\left(\mathrm{y}_{\mathrm{t}}-\mathrm{X}_{\mathrm{t}}^{\prime} \widehat{\phi}_{\mathrm{i}}^{*}\right)\left(\mathrm{y}_{\mathrm{t}}-\mathrm{X}_{\mathrm{t}}^{\mathrm{F}} \widehat{\phi}_{\mathrm{i}}^{*}\right)^{\mathrm{F}} /(\mathrm{n} ;-\mathrm{k})
$$

where (, ) $\Phi_{i}^{*}=\Phi i(\gamma d) ; n_{i}$ denotes the observations in regime $i, i=1,2$; and $k$ indicates the dimension of $X_{t}$ and $k<n$. The residual sum of squares is:

$$
S(\gamma, d)=S_{1}(\gamma, d)+S_{2}(\gamma, d), \quad S_{i}(\gamma, d)=\operatorname{trace}\left[\left(n_{i}-k\right) \widehat{\Sigma}_{\mathrm{I}}(\Gamma, \mathrm{D})\right]
$$

Where $\gamma$ and $\mathrm{d}$ are obtained from the following equation:

$$
\arg \min _{y, d} S(\gamma, d), 1 \leq d \leq d_{0} \text { and } \gamma \in R_{0}
$$

After attaining the optimal threshold value $(\gamma)$ and the delay parameter $(d)$, the best fit threshold model can be built.

\section{EMPIRICAL MODEL}

Assume that the long-run relationship between the farm and the retail market prices of rice is expressed by the equation $p^{R}{ }_{t}=$ $a+b p^{F}{ }_{t}+\varepsilon_{t} \cdot p^{F}$ is the logarithm of the farm price of rice, $p^{R}$ the logarithm of the retail price. a represents the price difference, and $\mathrm{b}$ the cross elasticity between the two prices. Generally, $b>1$, meaning that the variation in the retail price will be greater than the variation in the farm price.

According to von Carmon-Taubadel (1998) and Meyer (2004), the error correction term

$E C T_{t}=p^{R}{ }_{t}-a+b p^{F}{ }_{t}$ reflects the marketing margin between the farm and the retail markets. We therefore take into account a delay d and calculate $E C T_{t-d}$ as the threshold variable in the threshold error correction model. The causal relationship between changes in the farm price $\Delta \mathrm{p}^{\mathrm{F}}$ and the retail price $\Delta \mathrm{p}^{\mathrm{R}}$ is examined in the context of various changes in the marketing margin to understand market responses and the impact of government policies 5. Unlike Meyer (2004), who uses a delay of one and 
$E C T_{t-l}$ as his threshold variable, we use a strict statistical method to extract the correct delay d from the data itself, taking into account the particular features of the rice production cycle.

The threshold model is divided into two regimes. In one regime price adjustments are determined by the marketing margin (or rather, transaction cost deviations from the long-run equilibrium) that exceeds the threshold $\gamma$ (regime 1); in the other, adjustments are determined by the marketing margin below (and equal to) the threshold $\gamma$ (regime 2). The specification for the 2-regime TVECM is given below:

Regime 1 (high marketing margin)

$$
\left[\begin{array}{r}
\Delta p_{t}^{F} \\
\Delta p_{t}^{R}
\end{array}\right]=\left[\begin{array}{l}
\propto_{1} \\
\propto_{2}
\end{array}\right]+\sum_{i=1}^{k}\left[\begin{array}{c}
\beta_{i}^{F, F} \\
\beta_{i}^{R, F}
\end{array}\right.
$$

$$
\left.\underset{\beta_{i}^{R, R}}{{ }_{i}^{F, R}}\right]\left[\begin{array}{c}
\Delta p_{t-i}^{F} \\
{ }_{t} p_{t-i}^{R}
\end{array}\right]+\left[\begin{array}{c}
\emptyset_{1}^{F} \\
\emptyset_{1}^{R}
\end{array}\right]\left[E C T_{t-1}\right]+\left[\begin{array}{c}
\varepsilon_{t}^{F} \\
P \\
\varepsilon_{t}
\end{array}\right], \text { if } E C T_{t-d}>\gamma
$$

Regime 2 (low marketing margin)

$$
\left[\begin{array}{r}
\Delta p_{t}^{F} \\
\Delta p_{t}^{R}
\end{array}\right]=\left[\begin{array}{l}
\alpha_{1} \\
\propto_{2}
\end{array}\right]+\sum_{i=1}^{k}\left[\begin{array}{c}
\beta_{i}^{F, F} \\
\beta_{i}^{R, F}
\end{array}\right.
$$

$$
\left.\underset{\beta_{i}^{R, R}}{\beta_{i}^{F, R}}\right]\left[\begin{array}{c}
\Delta p_{t-i}^{F} \\
\Delta_{t-i}
\end{array}\right]+\left[\begin{array}{l}
\emptyset_{2}^{F} \\
\phi_{2}^{R}
\end{array}\right]\left[E C T_{t-1}\right]+\left[\begin{array}{c}
u_{t}^{F} \\
R \\
u_{t}^{R}
\end{array}\right], \text { if } E C T_{t-d} \leq \gamma
$$

Following Tsay (1998), we first assess a linear model in order to be certain that the data do contain thresholds, and that a threshold model is the most appropriate. Thus our null hypothesis is a linear VECM model, and the alternative hypothesis is a nonlinear TVECM mode

Finally, we tested for the Granger causality between the two variables in the short run within regime 1; this tests the effects of the marketing margin on the price transmission from the farm to the retailer. The Granger causality is tested using the Wald statistic, which is also known as the strong exogeneity test. The null hypothesis for the causality in regime 1 (regime 2) is $H_{0}: \beta^{F, R} i=0, i=1, \ldots, k\left(H_{0}: \delta^{F, R} i=0, i=1, \ldots, k\right)$. The null hypothesis states there is no causal relationship between $\Delta \mathrm{p}^{\mathrm{R}}{ }_{\mathrm{t}}$ and $\Delta \mathrm{p}^{F t}$; rejecting this null hypothesis implies that changes in the retail price do affect changes in the farm price. In the other direction, the null hypothesis is

$H_{0}: \beta^{R, F} i=0, i=1, \ldots, k\left(H_{0}: \delta^{R, F} i=0, i=1, \ldots, k\right)$, stating that $\Delta p^{F}{ }_{t}$ does not affect $\Delta p^{R}{ }_{t}$. Rejecting the null hypothesis implies that changes in the farm price do affect changes in the retail price.

We can use the adjustment coefficients, ${\phi p^{F}}_{1}$ and $\phi^{F}{ }_{2}$, on the ECTs at different intervals to determine whether the retail price is weakly exogenous with respect to the farm price; $\phi^{R}{ }_{1}$ and $\phi^{R}{ }_{2}$ can be used to determine whether the farm price is weakly exogenous with respect to the retail price. This assessment enables us to judge whether corrections emerge in response to short-run imbalances between the farm and the retail prices.

\section{EMPIRICAL RESULTS}

The variables in this model are the farm and the retail prices of the red onion. The monthly retail price and producer price data were collected from January 2005 to December 2014, a total of 120 observations. Table 1 reports the basic statistics of logarithmic farm and retail prices. The means of the two variables indicates that the fluctuation of the retail price is larger than that of the farm price. Figure 1 illustrates the time trends of the two prices and it is very obvious that the retail price is higher than the farm price. These two phenomena implies that there is the marketing margin (or transaction cost) between the farm and retail prices. The standard deviations of Table 1 could evaluate the price risk of the red onion prices. The numbers in Table 1 indicate that the farm price is riskier than the retail price is, which indicates that the red onion market that Sri Lankan farmers face is a low-return and high-risk one.

TABLE 1

THE BASIC STATISTICS OF THE PRICE VARIABLES

\begin{tabular}{|c|c|c|}
\hline & PP & RP \\
\hline Mean & 4.125939 & 4.584649 \\
\hline Std.Dev & .3587974 & .3509778 \\
\hline Skewness & .6242245 & .6097364 \\
\hline Kurotis & 3.204735 & 3.405052 \\
\hline observations & 120 & 120 \\
\hline
\end{tabular}

Note: Variables are all in natural logarithms. Variable PP the farm price per kilo (in Rupees) of red onion, RP is the retail price per kilo (in Rupees) of red onion. 
When conducting the tests, we first applied two unit root tests: the Augmented Dickey-Fuller and the Phillips-Perron tests, to establish that the variables were not stationary. The unit root tests compare constant and time-trend models. The results are shown in Table 2. They indicate that the two price series are I(1) processes, i.e. the first difference of the two series are stationary. Using these results, we can test for co integration between the farm and the retail rice prices.

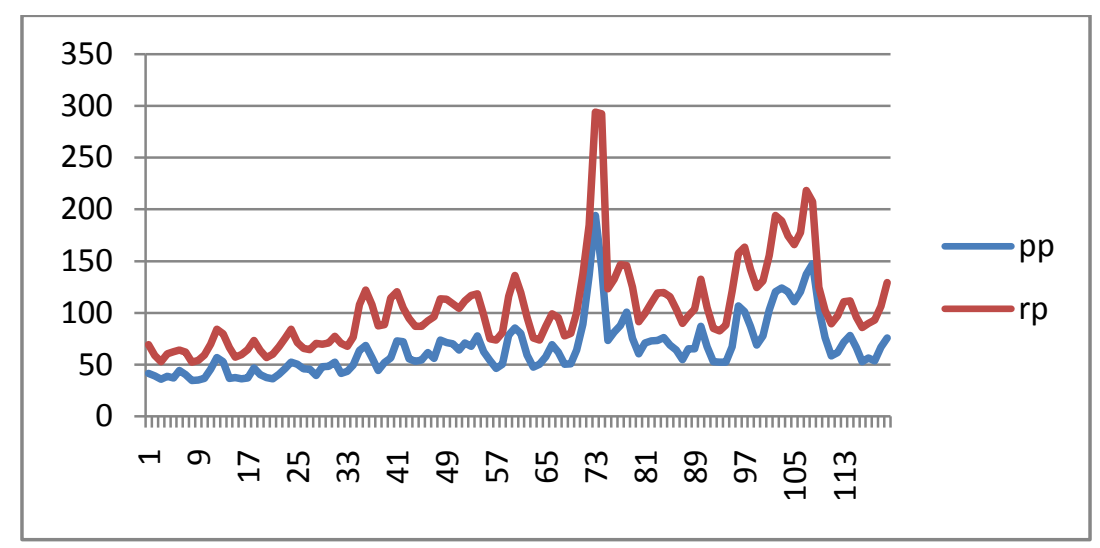

FIGURE 1: FARM AND RETAIL PRICES OF RED ONION

TABLE 2

UNIT ROOT TESTS

\begin{tabular}{|c|c|c|}
\hline & \multicolumn{2}{|c|}{ ADF } \\
\hline Variable & Constant & \multicolumn{2}{c|}{ Constant + trend } \\
\hline \multicolumn{3}{|c|}{ Level value } \\
\hline RP & $-1.797(10)$ & $-3.93(2)$ \\
\hline PP & $-2.114(3)$ & $-5.632(9) * * *$ \\
\hline RP & First difference & $-10.994(2) * * *$ \\
\hline PP & $-9.14(2) * * *$ & $-11.02(2) * * *$ \\
\hline
\end{tabular}

Notes: Variables are natural logarithms. A maximum of 15 lags were used in the unit root tests. The numbers in brackets [ ] are the appropriate lag lengths selected by AIC. *** indicate significance at the 1 percent level. The critical value for ADF test with constant and constant plus time trend is 4.04 and 3.51 respectively. Critical values from MacKinnon (1996).

The Johansen co integration test (Johansen, 1991; 1995) was applied to determine whether or not there is a stable long-run relationship between the farm gate price and retail price of red onion The results of the unit root tests showed no trend, implying that the $I(1)$ process was not caused by a time trend. We therefore did not consider time trends in the cointegration test. Table 3 shows the results of the cointegration test: the farm and the retail prices are cointegrated. The long-run relationship between the farm and the retail prices is $p_{1, t}^{R}=29.45+-1.238247 p_{1, t}^{F}$. The parameter value of a shows that there exists a fixed mark-up effect; the value of $b$ shows that the cross-elasticity between the farm and the retail prices is higher than 1 . This implies that variation in the retail price of red onion is larger than the variations in the farm price.

TABLe 3

CO-INTEGRATING TEST

\begin{tabular}{|c|c|c|c|c|}
\hline \multicolumn{5}{|c|}{ Unrestricted Cointegration Rank Test (Trace) } \\
\hline Hypothesized & & Trace & 0.05 & Prob.** \\
\hline No. of CE(s) & Eigenvalue & Statistic & Critical Value & 0.0079 \\
\hline None $*$ & 0.177504 & 31.88568 & 25.87211 & 0.0892 \\
\hline At most 1 & 0.097498 & 10.97658 & 12.51798 & \\
\hline \multicolumn{5}{|c|}{ Unrestricted Cointegration Rank Test (Maximum Eigenvalue) } \\
\hline Hypothesized & \multicolumn{5}{|c|}{ Max-Eigen } & 0.05 & Prob.** \\
\hline No. of CE(s) & Eigenvalue & Statistic & Critical Value & 0.0299 \\
\hline None * & 0.177504 & 20.90911 & 19.38704 & 0.0892 \\
\hline At most 1 & 0.097498 & 10.97658 & 12.51798 & \\
\hline
\end{tabular}


Before defining the nonlinear threshold model, it is necessary to confirm that the variables are not in fact linear. We follow Hansen and seo (2002) in testing for linearity: This is the test of Test of linear cointegration vs threshold cointegration. The test statistic value is 39.2 which is significant at $1 \%$ level. We follow seo (2006) to test cointegration. This is the test of Test of no cointegration vs threshold cointegration. The test statistic value is 25.3151 which is significant at $5 \%$ level. The error term $\left(\mathrm{ECT}_{\mathrm{t}-\mathrm{d}}\right)$, taken to be a measure of the marketing margin is the threshold variable. We first selected the 4 lag period ( $\mathrm{p}$ ) which gave the best fit for the data as measured by the Akaike information criterion (AIC)..

The threshold variable for the red onion was therefore $\mathrm{ECT}_{\mathrm{t}-2}$; The threshold value for red onion model is 0.081 ; therefore when $\mathrm{ECT}_{\mathrm{t}-1}>-0.148$, the regime relating to the high marketing margin (regime 1) holds. When $\mathrm{ECT}_{\mathrm{t}-1}<-0.148, \mathrm{the}$ marketing margin is low (regime 2). The economic interpretation of these findings is that when the marketing margin is lower than the threshold value, the market operates freely: there is feedback between the farm and the retail prices. When the marketing margin is higher than the threshold value, there is no significant causal relationship between the two prices. We suggest that the reason for this difference is that the government makes necessary interventions in the market to stabilize the retail price when there is a large rise in the retail price. That rise may originally have been caused by changes in the farm price, but after the government intervention, a causal relationship between the two prices no longer exists. This is consistent with normal practice of the agriculture authorities in Sri Lanka.

\section{CONCLUSION}

The purpose of this study is to examine the relationship between the farm and the retail prices in the Sri Lankan red onion market. We established three hypotheses and obtained several important empirical findings. Firstly, there is a long-run cointegration relationship between the farm and the retail prices. Secondly, the marketing margin resulting from this long-run relationship may cause short-run dynamic adjustments between the farm and the retail prices, which results in the asymmetric causality.

This implies that the marketing margin is an important factor when analyzing the causality in the farm and the retail markets. Because of this, we constructed a nonlinear threshold model to fully understand the effect of the marketing margin. Thirdly, when the marketing margin is low, the market operates freely; when the marketing margin is high, the government makes necessary interventions in the market to prevent excessive rises in the rice prices. When intervention occurs, the market system no longer operates.

\section{ACKNOWLEDGEMENTS}

The success and final outcome of this project required a lot of guidance and assistance from many people and I am extremely privileged to have got this all along the completion of my project. All that I have done is only due to such supervision and assistance and I would not forget to thank them.

I respect and thank Dr.K.Sooriyakumar (Head, Department of Agricultural Economics, Faculty of Agriculture, University Of Jaffna, Sri Lanka), for providing me an opportunity to do the project work in Department of Agricultural Economics, Faculty of Agriculture, University Of Jaffna and giving us all support and guidance which made me complete the project duly.

I would not forget to remember Miss.Vasanthiny Jeevaratnam (Department of Agricultural Engineering, Faculty of Agriculture, University Of Jaffna, Sri Lanka) for their encouragement and more over for their timely support and guidance till the completion of our project work.

\section{REFERENCES}

[1] Johansen, S. (1991) "Estimation and Hypothesis Testing of Cointegration Vectors in Gaussian Vector Autoregressive Models", Econometrica, 59, pp. 1551-1580.

[2] Obstfeld, M., Taylor, A. M. (1997) "Non-linear Aspects of Goods Market Arbitrage and Adjustment: Heckscher's Commodity Points Revisited", Journal of the Japanese and international economies, 11, pp. 441-479.

[3] Frey, G., Manera, M. (2007) "Econometric Models of Asymmetric Price Transmission”, Journal of Economic Surveys, 21(2), pp. 349-415

[4] Phillips, P. C. B., Perron, P. (1988) “Testing for a Unit Root in Time Series Regression”, Biometrika, 75, pp. 335 -346.

[5] Von Carmon-Taubadel, S. (1998) "Estimating Asymmetric Price Transmission with the Error Correction Representation: an Application to the German Pork Market", European Review of Agricultural Economics, 25, pp. 1-18.

[6] Johansen, S. (1991) "Estimation and Hypothesis Testing of Cointegration Vectors in Gaussian Vector Autoregressive Models", Econometrica, 59, pp. 1551-1580. 
[7] MacKinnon, J. G. (1996) "Numerical Distribution Functions for Unit Root and Cointegration Tests", Journal of Applied Econometrics, 11, pp. 601-618.

[8] Ben-Kaabia, M., Gil, J. M., Boshnjaku, L. (2002) Price Transmission Asymmetries in the Lamb Sector in Spain. In: Proceedings of the Xth EAAE Conference, Zaragoza.

[9] Frey, G., Manera, M. (2007) "Econometric Models of Asymmetric Price Transmission”, Journal of Economic Surveys, 21(2), pp. 349-415.

[10] http://www.freshplaza.com/article/100604/Sri-Lanka-Oversupply-hits-onion-market

[11] https://www.alibaba.com/showroom/onion-price-for-sri-lanka.html

[12] http://snapcart.lk/price-updates/daily-vegetable-prices.php

[13] https://www.doa.gov.lk/index.php/en/

[14] http://www.harti.gov.lk/index.php/en/market-information/weekly-food-commodities-bulletin 